\title{
OPTIMASI DESAIN TERMOHIDROLIKA TERAS DAN SISTEM PENDINGIN REAKTOR RISET INOVATIF DAYA TINGGI
}

\author{
Endiah Puji Hastuti, M. Subekti, Sukmanto Dibyo, M. Darwis Isnaini \\ PTKRN-BATAN, Gedung 80 Kawasan PUSPIPTEK-Serpong, Tangerang Selatan, 15310 \\ email: endiah@batan.go.id \\ Diterima editor: 18 Agustus 2015 \\ Direvisi editor: 31 Agustus 2015 \\ Disetujui untuk publikasi: 10 September 2015
}

\begin{abstract}
ABSTRAK
OPTIMASI DESAIN TERMOHIDROLIKA TERAS DAN SISTEM PENDINGIN REAKTOR RISET INOVATIF DAYA TINGGI. Implementasi reaktor inovasi telah diterapkan pada berbagai reaktor riset baru yang saat ini sedang dibangun. Pada saat ini BATAN sedang merancang desain konseptual reaktor riset daya tinggi yang telah masuk pada tahap optimasi desain. Spesifikasi desain konseptual reaktor riset inovatif adalah reaktor tipe kolam berpendingin air dan reflektor $\mathrm{D}_{2} \mathrm{O}$. Teras reaktor memiliki kisi $5 \times 5$ dengan 16 bahan bakar dan 4 batang kendali. Teras reaktor berada di dalam tabung berisi $\mathrm{D}_{2} \mathrm{O}$ yang berfungsi sebagai posisi iradiasi. Daya reaktor $50 \mathrm{MW}$ didesain untuk membangkitkan fluks neutron termal sebesar $5 \times 10^{14}$ $\mathrm{n} / \mathrm{cm}^{2} \mathrm{~s}$. Teras reaktor berbentuk kompak dan menggunakan bahan bakar $\mathrm{U}_{9} \mathrm{Mo}-\mathrm{Al}$ dengan tingkat muat uranium 7-9 $\mathrm{gU} / \mathrm{cm}^{3}$. Desain termohidrolika yang mencakup pemodelan, perhitungan dan analisis kecukupan pendingin dibuat sinergi dengan desain fisika teras agar keselamatan reaktor terjamin. Makalah ini bertujuan menyampaikan hasil analisis perhitungan termohidrolika teras dan sistem reaktor riset inovatif pada kondisi tunak. Analisis dilakukan menggunakan program perhitungan yang telah tervalidasi, masing-masing adalah Caudvap, PARET-ANL, Fluent dan ChemCad 6.4.1. Hasil perhitungan menunjukkan bahwa pembangkitan panas yang tinggi dapat dipindahkan tanpa menyebabkan pendidihan dengan menerapkan desain teras reaktor bertekanan, di samping itu desain awal komponen utama sistem pembuangan panas yang terintegrasi telah dilakukan, sehingga konseptual desain termohidrolika RRI-50 dapat diselesaikan.
\end{abstract}

Kata kunci : reaktor riset inovatif, Caudvap, PARET-ANL, Fluent, ChemCad 6.4.1.

\section{ABSTRACT}

THERMALHYDRAULIC DESIGN AND COOLING SYSTEM OPTIMIZATION OF THE HIGH POWER INOVATIVE RESEARCH REACTOR. Reactor innovation has been implemented in a variety of new research reactors that currently are being built. At this time BATAN is designing a conceptual design of the high power research reactor which has entered the stage of design optimization. The conceptual design specifications of the innovative research reactor is a pool type reactor, water-cooled and reflected by $\mathrm{D}_{2} \mathrm{O}$. The reactor core has a $5 \times 5$ grid with 16 fuels and 4 control rods, which is inserted into a tube containing $\mathrm{D}_{2} \mathrm{O}$ as an irradiation position. Reactor power of $50 \mathrm{MW}$ is designed to generate thermal neutron flux of $5 \times 10^{14} \mathrm{n} / \mathrm{cm}^{2}$ s. The compact core reactor is using $U_{9} M o-A l$ fuel with uranium loading of 7-9 $\mathrm{gU} / \mathrm{cm}^{3}$. Thermal hydraulic design includes modeling, calculation and analysis of the adequacy of coolant created synergy with the physical design of reactor safety. This paper aims to deliver the results of thermal hydraulic calculation and system design analysis at steady state condition. The analysis was done using various calculation programs that have been validated, i.e. Caudvap, PARET-ANL, Fluent and ChemCad 6.4.1. The calculation results show that the heat generation can be transfered without causing a two phase flow boiling by applying pressurized reactor core design, while the main components of initial design system with an integrated heat dissipation has been done, to complete the conceptual design of the RRI-50 thermalhydraulics.

Keywords : inovative research reactor, Caudvap, PARET-ANL, Fluent, ChemCad 6.4.1. 


\section{PENDAHULUAN}

BATAN tengah melaksanakan kegiatan litbang teknologi reaktor, salah satunya adalah penyusunan desain konseptual reaktor riset inovatif. Ketentuan desain reaktor riset yang akan dibuat telah dituangkan dalam dokumen kriteria pengguna (user criteria design, UCD) Reaktor Riset Inovatif [1]. Implementasi reaktor inovasi telah diterapkan pada berbagai reaktor riset baru yang saat ini telah dan sedang dibangun. Berbagai upaya dilakukan untuk memperoleh fluks neutron yang tinggi dengan daya reaktor yang diupayakan rendah, seperti penggunaan teras reaktor dengan susunan bahan bakar yang lebih kompak, dan penggunaan moderator air berat $\mathrm{D}_{2} \mathrm{O}$. Kecenderungan teknologi reaktor sebagai faktor kunci dari aspek desain fisika reaktor yang digunakan pada reaktor riset inovatif baru antara lain adalah aspek bahan bakar nuklir, aspek daya dan aspek pemilihan jenis reflektor.

Ditinjau dari aspek bahan bakar nuklir, terdapat kecenderungan menggunakan bahan bakar $\mathrm{U}_{3} \mathrm{Si}_{2} \mathrm{Al}$ dengan pengayaan rendah $19,75 \%$ dan tingkat muat $4,8 \mathrm{~g} \mathrm{U} / \mathrm{cc}$, akan tetapi juga diantisipasi untuk dapat menggunakan bahan bakar UMo apabila penelitian mengenai bahan bakar ini telah dapat diaplikasikan. Bahan bakar yang digunakan antara lain berbentuk pelat, baik pelat persegi paralel, kurva paralel maupun pelat silinder. Reaktor Jules Horowitz yang sedang dibangun di Perancis oleh konsorsium Eropa ditujukan sebagai material testing reaktor, selain untuk memenuhi kebutuhan radioisotop Eropa. Daya reaktor yang dipilih rata-rata berskala sedang, 20MW. Agar diperoleh fluks neutron yang tinggi maka dipilih moderator sekaligus reflektor $\mathrm{D}_{2} \mathrm{O}$. Reaktor jenis ini digunakan untuk keperluan yang lebih luas seperti uji material untuk reaktor temperatur tinggi, untuk mendukung tujuan tersebut dipilih kombinasi antara daya tinggi dan penggunaan reflektor $\mathrm{D}_{2} \mathrm{O}$. Fluks neutron yang digunakan rata rata berorde $10^{14}$ hingga $10^{15} \mathrm{n} / \mathrm{cm}^{2} \mathrm{~s}[1]$.

Reaktor Riset Inovatif yang konseptual desainnya dilakukan BATAN berupa reaktor tipe kolam bertekanan, berpendingin air ringan dengan reflektor air berat, $\mathrm{D}_{2} \mathrm{O}$. Reaktor memiliki fluks neutron termal rerata sebesar $5 \times 10^{14} \mathrm{n} / \mathrm{cm}^{2} \mathrm{~s}$. Fluks neutron yang tinggi dicapai melalui konsep desain teras kompak dimana teras dikelilingi oleh reflektor yang memiliki fluks neutron tinggi, reflektor ini juga berfungsi sebagai tempat untuk fasilitas iradiasi. Bahan bakar yang digunakan adalah jenis molybdenum $\left(\mathrm{U}_{9} \mathrm{Mo}-\mathrm{Al}\right)$ berpengayaan rendah $(<20 \%)$ dengan tingkat muat 360 gram. Desain reator ini ditujukan untuk menyiapkan reaktor baru yang berorientasi pada reaktor masa depan mengikuti perkembangan teknologi reaktor terkini seperti dipersyaratkan pada dokumen [1].

Perhitungan desain neutronik teras reaktor riset inovatif telah mengerucut pada hasil optimalnya yang sesuai dengan dokumen UCD, melalui berbagai tahap pengujian desain alternatif. Seiring dengan capaian tersebut, maka desain termohidrolika teras reaktor dan sistem juga harus dioptimasi. Analisis kemampuan pengambilan panas di dalam teras reaktor sesuai desain dengan konfigurasi bahan bakar yang dihasilkan. Hal ini akan menjadi umpan balik bagi desain konfigurasi teras reaktor, hingga diperoleh kesesuaian antara desain konfigurasi dan kemampuan pengambilan panasnya.

Penelitian desain reaktor baru mengenai kemajuan dan arah riset termohidrolika telah dilakukan. Saha P. dkk. (2013) menyampaikan hasil panel diskusi para ahli mengenai arah riset termohidrolika dan pengembangan PLTN ke depan, yang diselenggarakan pada konferensi NURETH-14 di Toronto, Canada, September 2011. Dalam pertemuan tersebut dibahas mengenai isu-isu termohidrolika terkait dengan pengoperasian dan perkembangan reaktor maju. Isu yang disampaikan pada konferensi tersebut bahwa pada saat ini arah penelitian dan pengembangan dalam bidang termohidrolika berlanjut terus. Litbang termohidrolika reaktor antara lain dilakukan dalam bidang eksperimental dan komputasi untuk pengoperasian reaktor. Hal tersebut dilakukan pada reaktor yang sedang dibangun, dan reaktor yang siap dioperasikan dalam jangka pendek, serta reaktor Generasi IV. Dengan peningkatan kemampuan komputasi, pemodelan komputasi multifisika dalam fine-scale, yang dikopel dengan kode analisis sistem. Hal ini diharapkan mampu memberikan jawaban terhadap berbagai masalah yang menantang, baik pada operasi reaktor maupun desain reaktor maju [2].

Pengembangan komputasi termohidrolika pada reaktor riset baru juga banyak dilakukan. Daesong Jo dkk. (2014) mengembangkan program perhitungan termohidrolika perangkat bahan bakar tipe pelat TMAP-1.0. Pengembangan dilakukan untuk menghitung karakteristika 
termohidrolika dan batas termal moda pendinginan konveksi paksa dan konveksi bebas pada kondisi tunak. Analisis dilakukan pada kanal pendingin bahan bakar, menggunakan analisis satu dimensi untuk memprediksi karakteristika termohidrolika dalam kanal bahan bakar. Pada konveksi paksa arah aliran ke bawah (downward), sedangkan pada moda pendinginan konveksi bebas arah aliran ke atas (upward). Kondisi terparah di dalam teras reaktor disimulasi dengan menggunakan faktor teknis, faktor puncak daya aksial dan radial. Marjin termal awal pendidihan inti (onset of nucleate boiling, ONB), dan rasio akhir pendidihan inti (departure from nucleate boiling ratio, DNBR). Hasil perhitungan pada moda pendinginan konveksi paksa dibandingkan dengan hasil eksperimental. Untuk analisis pendinginan konveksi bebas, kecepatan pendingin yang dihasilkan dari kesetimbangan gaya apung dan gaya gesek diprediksi dari hasil analisis program TMAP-1.0 dibandingkan dengan program RELAP5/MOD3. Hasil analisis menunjukkan kesesuain, pada kondisi konveksi paksa maupun konveksi alam [3]. Sementara itu Qing Lu dkk. (2009) mengembangkan program Thac-PRR untuk perpindahan panas pada bahan bakar jenis pelat. Penyelesaian perpindahan panas menggunakan persamaan dasar konservasi massa, momentum dan energi, dengan korelasi faktor gesekan aliran, perpindahan panas dan sifat termo-fisika. Program ini juga dapat digunakan untuk menghitung RIA dan LOFA, serta telah dilakukan benchmarking dengan IAEA 10mW MTR. Selain itu juga dilakukan benchmarking terhadap penyumbatan parsial (95\%) dan jumlah penyumbatan satu saluran (100\%). Hasil penelitian menunjukkan bahwa perlunya mempertimbangkan interaksi antara saluran yang tersumbat dan saluran di sampingnya pada saat transien [4]. Barati (2013) mengevaluasi fungsi keandalan teras Teheran Research Reactor pada operasi normal untuk memperoleh data kerusakan yang mencukupi pada kondisi operasi yang spesifik. Model interference resistance-stress atau load-capacity, digunakan dalam kerangka keandalan struktur. Evaluasi dilakukan dengan program RELAP5/Mod 3.2 menggunakan metode Latin Hypercube Sampling (LHS) sebagai metode kuantifikasi. Menurut hasil penelitian, dua kondisi kegagalan akan terjadi apabila kanal terpanas melampaui temperatur $65,1^{\circ} \mathrm{C}$ dan $58,9^{\circ} \mathrm{C}$ sedangkan kanal rerata $50,4^{\circ} \mathrm{C}$ dan $45,6^{\circ} \mathrm{C}$, sebagai batas atas dan bawah. Sesuai hasil eksperimen nilai keandalan terhitung sebesar $9.1 \mathrm{e}^{01}$ dengan tingkat kepercayaan $95 \%$, hal tersebut menunjukkan bahwa nilai parameter koefisien perpindahan panas bahan bakar memberikan efek signifikan [5]. Ardaneh (2013) memprediksi respon dinamika reaktor MTR mengikuti RIA tak terproteksi pada kondisi konveksi alam. Dengan cara menyamakan model parameter efek kinetika dan termohidrolika yang disederhanakan. Karakteristika keselamatan inheren pada reaktor riset tipe MTR menggunakan moda pendinginan konveksi bebas jelas ditunjukkan menggunakan ekspansi model. ONB dipilih sebagai marjin keselamatan pengoperasian reaktor, dari pemodelan ini diperoleh insersi reaktivitas yang melebihi nilai $0,73 \$$ akan menyebabkan terlampauinya nilai batas tersebut [6].

Selain pembuatan dan benchmarking kode komputasi, beberapa peneliti juga melakukan eksperimen termohidrolika pada reaktor riset berbahan bakar tipe pelat. Dixita dkk. (2013) mempelajari mengenai penomena instabilitas aliran pada saat reaktor start-up, menggunakan fasilitas eksperimen terskala. Pengujian dilakukan pada kondisi tunak dengan dan tanpa umpan balik reaktivitas, dilakukan dengan tekanan sistem yang berbeda. Pada pengujian tersebut diperoleh aliran pendingin yang stabil di berbagai tingkat daya reaktor, tanpa memperhitungkan inlet kanal subcooling. Untuk daerah/region aliran yang tidak stabil akan berkurang secara signifikan pada daerah aliran yang bertekanan tinggi dibandingkan pada kasus tekanan rendah. Sehingga kondisi batas high subcooling menjadi tidak efektif. Kondisi batas subcooling yang tinggi tidak dipengaruhi oleh umpan balik reactivity void. Ketika inlet subcooling menurun, maka daya mulai berosilasi dengan beberapa frequensi dan meningkatkan amplitudo osilasi kecepatan aliran. Dari hasil studi diketahui bahwa daya pendingin (coolant power) dapat berosilasi karena adanya fraksi void. Dimana sistem dapat stabil atau tidak akan bergantung pada waktu konstan batang kendali [7]. Sementara Jian Maa dkk. (2011) melakukan studi aliran fasa tunggal dan perpindahan panas pada kanal sempit persegi menggunakan air deionisasi sebagai fluida kerja. Studi ini dilakukan karena adanya beberapa perbedaan dengan teori konvensional. Parameter yang divariasikan adalah laju alir massa, temperatur inlet, dan fluks panas. Berdasarkan pada hasil pengukuran temperatur, laju alir masa, pressure drop and fluks panas, dilakukan perhitungan faktor friksi isotermal dan nonisotermal, bilangan Nusselt lokal dan rerata. Dari hasil tersebut telah dilakukan pengembangan 
korelasi faktor friksi isotermal dan bilangan Nusselt rerata, dimana diperoleh hasil yang sesuai dengan teori konvensional. Meskipun demikian nilai eksponen (m) untuk modifikasi efek variabel properti perlu dikembangkan [8]. Jian Zhang dkk. (2015) mempelajari mengenai kapasitas pendinginan sirkulasi alam melalui eksperimental di reaktor riset universitas Kyoto (KURR), dengan cara mengukur temperatur inlet dan outlet teras dan memasang 8 termokopel pada outlet bahan bakar dengan variasi daya $10 \mathrm{~kW}$ hingga $100 \mathrm{~kW}$, tanpa aliran pendingin. Penelitian ini bertujuan untuk mempelajari distribusi temperatur ke luar teras reaktor. Hasil pengukuran menunjukkan adanya kesesuaian antara distribusi cross-sectional dengan distribusi output termal elemen bakar dalam teras reaktor. Pencampuran antara air panas dan air dingin terjadi terjadi pada daerah $5 \mathrm{~cm}$ dari outlet teras [9].

Penelitian mengenai desain RRI-50 telah berlangsung sejak tahun 2011. Sebelumnya telah dilakukan kajian mengenai analisis distribusi laju alir desain teras reaktor riset berbahan bakar tingkat muat tinggi, dimana basis daya yang digunakan adalah $20 \mathrm{MW}$ dengan berbagai konfigurasi teras alternatif [1]. Pada penelitian berikutnya dilakukan analisis aspek termohidrolika pada desain awal bahan bakar reaktor riset inovatif dengan daya tinggi. Pada penelitian ini karakteristika termohidrolika teras dianalisis pada daya $50 \mathrm{MW}$ dengan menggunakan input berupa asumsi dengan variabel tekanan, laju pendingin dan daya reaktor [1]. Seiring dengan hasil yang dicapai pada optimasi perhitungan fisika teras, maka analisis yang sinergis harus dilakukan dengan optimasi desain termohidrolika secara menyeluruh baik teras maupun sistem pendingin reaktor. Makalah ini bertujuan menyampaikan hasil desain perhitungan termohidrolika teras dan sistem reaktor riset inovatif pada kondisi tunak. Fokus kegiatan tersebut dilakukan melalui pemodelan, perhitungan dan analisis meliputi perhitungan (a) distribusi pendingin pada konfigurasi teras reaktor terpilih, (b) analisis keselamatan termohidrolika teras, (c) profil perpindahan panas pelat elemen bakar 3D, dan (d) desain sistem pendingin RRI. Analisis dilakukan menggunakan program perhitungan yang telah tervalidasi, masing-masing adalah Caudvap, PARET-ANL, Fluent dan ChemCad 6.4.1.

\section{TEORI}

\section{Konfigurasi Teras Reaktor Riset Inovatif}

Parameter utama desain konseptual reaktor riset inovatif adalah reaktor tipe kolam berpendingin air bertekanan dan menggunakan reflektor $\mathrm{D}_{2} \mathrm{O}$. Teras reaktor memiliki kisi $5 \times 5$ dengan 16 bahan bakar dan 4 batang kendali dan 5 kolom air. Elemen teras berisi 16 buah elemen bakar, 4 elemen kendali, dan 5 buah kolom air di dalam teras, dengan panjang bahan bakar dan kendali masing-masing $70 \mathrm{~cm}$. Jumlah pelat elemen bakar dalam 1 elemen bakar adalah 21 pelat, sedangkan jumlah pelat di dalam elemen kendali adalah 15 pelat. Pada desain elemen kendali masing-masing 3 pelat yang berada di pinggir, diganti dengan absorber berbentuk persegi. Teras reaktor berada di dalam tabung berisi $\mathrm{D}_{2} \mathrm{O}$ yang sekaligus berfungsi sebagai posisi iradiasi yang ditunjukkan pada Gambar 1. Konfigurasi elemen teras berbentuk kompak. Diameter teras aktif 40 $\mathrm{cm}$ dengan diameter reflektor tabung $\mathrm{D}_{2} \mathrm{O}$ sebesar $2 \mathrm{~m}$ dengan tinggi $1,5 \mathrm{~m}$ dan diameter kolam $5 \mathrm{~m}$. RRI menggunakan bahan bakar $\mathrm{U}_{9} \mathrm{Mo}-\mathrm{Al}$ dengan tingkat muat $360 \mathrm{~g}$, fuel loading 6,6 kg dan menggunakan batang kendali Ag-In-Cd tipe follower. Kerapatan uranium untuk teras RRI menggunakan nilai kerapatan rendah, karena kalau melebih kerapatan tersebut nilai margin padam minimum kurang dari batas $-0,5 \% \Delta \mathrm{k} / \mathrm{k}[1,10]$. 


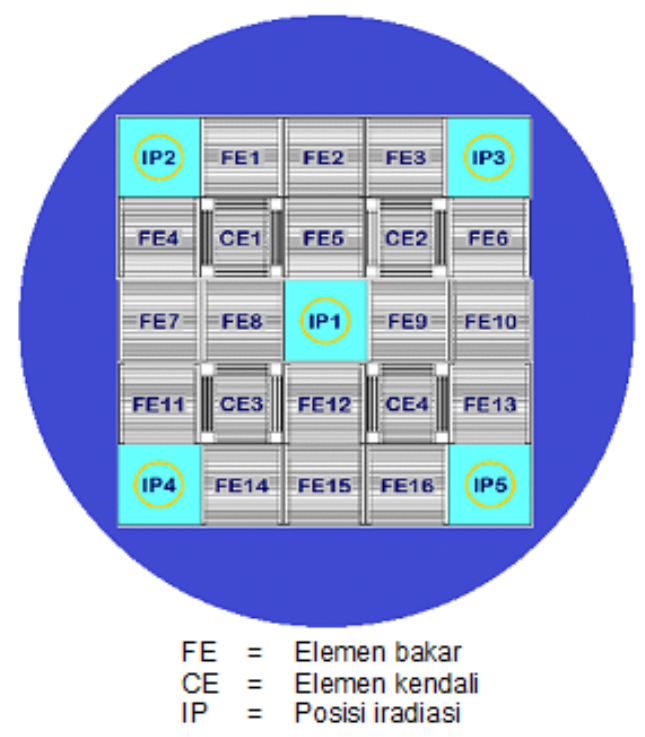

Gambar 1. Konseptual desain konfigurasi teras RRI [10].

\section{Sistem Pendingin Reaktor Riset Inovatif}

Untuk mempertahankan pendinginan sirkulasi paksa selama operasi normal, sistem pendingin primer dilengkapi dengan 3 pompa sentrifugal (dua pompa beroperasi, dengan satu pompa standby). Pompa-pompa tersebut mengalirkan air pendingin primer dengan arah ke bawah ke dalam teras reaktor melalui hotleg, dan selanjutnya menuju ke tangki tunda (delay chamber). Tangki tunda didesain untuk mampu meluruhkan radioisotop N-16 pada tingkat aman. Pendingin primer keluar dari tangki tunda kemudian memindahkan panasnya ke penukar panas (heat exchanger) dan kembali ke kolam reaktor melalui ring distributor, dari ring distributor ini air disemprotkan ke dalam teras reaktor.

Untuk menjamin kecukupan pendingin saat pengambilan panas sisa akibat kehilangan aliran pendingin (loss of flow accident, LOFA), pompa dilengkapi dengan roda gila (fly wheel). Di samping itu mengingat panas peluruhan (decay heat) masih cukup besar maka sistem pendingin teras darurat harus beroperasi secara otomatis. Untuk menjamin agar teras reaktor tergenang air pendingin ketika terjadi kehilangan pendingin (loss of coolant accident, LOCA), pipa suction sistem primer dilengkapi dengan antisiphon break equipment. Instalasi antisiphon break equipment di dalam pipa suction didesain sedemikian rupa, sehingga pada kejadian kecelakaan apapun, reaktor selalu tergenangi oleh air. Di samping itu, pada kondisi normal, laju alir ke dalam teras reaktor akan berefek secara signifikan. Untuk memenuhi hal ini, pipa suction dilengkapi dengan pipa antisiphon [10].

\section{METODOLOGI}

\section{Program Perhitungan}

Analisis termohidrolika ini melibatkan empat program perhitungan yang telah tervalidasi yaitu CAUDVAP, PARET-ANL, FLUENT dan CHEMCAD. Program CAUDVAP moda 2.60 dikembangkan untuk desain hidrolika teras reaktor riset. Program ini menghitung distribusi kecepatan aliran kondisi tunak melalui berbagai kanal pendingin yang saling terkoneksi, secara paralel, antara plenum inlet dan outlet. Parameter hasil hitungan berupa pressure drop total teras reaktor dengan input flow total, distribusi aliran di berbagai kanal pendingin dan gesekan serta hilang aliran di setiap bagian aliran.

Program komputer PARET-ANL merupakan program yang dirancang untuk memprediksi kejadian dan akibat dari suatu kecelakaan teras reaktor pada kondisi tunak dan transien. Program 
ini menggabungkan aspek-aspek neutronik, hidrodinamik dan perpindahan panas. Paket program PARET-ANL dapat digunakan untuk memodelkan reaktor dalam bentuk geometri silinder ataupun persegi. Daerah teras reaktor dapat dibagi menjadi tiga bagian dengan masing-masing tingkat daya aliran pendingin yang berbeda. Pada masing-masing daerah, ke arah radial dapat direpresentasikan sebanyak 44 titik, sedangkan ke arah aksial sampai 21 titik aksial yang merepresentasikan perbedaan rapat daya yang berbeda.

FLUENT adalah program perhitungan dinamika fluida tiga dimensi (computational fluid dynamic 3 dimension, CFD-3D) berbasis volume hingga (finite volume) yang mampu memprediksi dan menganalisis fenomena dinamika aliran fluida secara teliti dan memberikan visualisasi yang baik.

CHEMCAD 6.4.1 adalah program perhitungan yang digunakan untuk mendesain proses dalam suatu instalasi industri. Software simulasi dilengkapi dengan pustaka komponen kimia, metode termodinamika, beberapa standar internasional untuk desain dan bahan untuk membuat ukuran sebuah penukar panas, pemipaan dan unit operasi. Program ini memungkinkan dilakukan simulasi steady-state dari proses kimia yang berkesinambungan dari skala laboratorium ke skala penuh. CHEMCAD 6.4.1 juga memungkinkan perhitungan sifat fisik dan kesetimbangan fasa untuk komponen murni dan campuran.

\section{Input Data}

Input data yang digunakan dalam perhitungan CAUDVAP, PARET-ANL dan FLUENT berupa data geometri teras dan elemen teras seperti ditunjukkan pada Tabel 1, sedangkan data parameter termohidrolika ditunjukkan pada Tabel 2. Desain sistem pendingin RRI-50, menggunakan data hasil perhitungan kecukupan pendingin untuk memindahkan panas dari sistem pendingin primer ke sistem pendingin sekunder.

Tabel 1. Data geometri perangkat bahan bakar dan batang kendali reaktor RRI [10].

\begin{tabular}{clll}
\hline No. & PARAMETER & & NILAI \\
\hline 1 & Jumlah elemen bakar standar di dalam teras & $:$ & 16 \\
2 & Pelat elemen bakar per elemen bakar standar & $:$ & 21 \\
3 & Jumlah elemen bakar kendali pada teras & $:$ & 4 \\
4 & Pelat elemen bakar per elemen bakar kendali & $:$ & 15 \\
5 & Dimensi elemen bakar standar (EB) dan kendali & $:$ & $77,1 \times 81 \times 700$ \\
& (EK), mm & $:$ & 1,3 \\
6 & Ketebalan pelat bahan bakar, mm & $:$ & 2,55 \\
7 & Lebar kanal pendingin, mm & $:$ & 21 \\
8 & Jumlah pelat bahan bakar di EB & $:$ & 15 \\
9 & Jumlah pelat bahan bakar di EK & $:$ & $\mathrm{AlMg}$ \\
10 & Material kelongsong & $:$ & $\mathrm{AlMg}$ \\
11 & Material pelat sisi & $:$ & 0,38 \\
12 & Ketebalan kelongsong bahan bakar, mm & $:$ & $0,54 \times 62,75 \times 700$ \\
13 & Dimensi zona aktif $($ meat $)$, mm & $:$ & $\mathrm{U}_{9} \mathrm{Mo}-\mathrm{Al}$ \\
14 & Material bahan bakar & $:$ & 19,75 \\
15 & Pengkayaan, $\%$ & $:$ & 360 \\
16 & Muatan massa ${ }^{235} \mathrm{U}, \mathrm{g}$ & $:$ & $\mathrm{Ag}-\mathrm{In}-\mathrm{Cd}$ \\
17 & Material penyerap & $:$ & 3,38 \\
18 & Ketebalan penyerap, mm & $:$ & $\mathrm{SS}-321$ \\
19 & Material kelongsong penyerap & $:$ & 0,85 \\
20 & Ketebalan kelongsong penyerap & $:$ & 0,054 \\
21 & Tebal meat, cm & $:$ & 0,038 \\
22 & Tebal kelongsong, cm & $:$ & 0,255 \\
23 & Lebar kanal pendingin, cm & $:$ & $8,1 \times 7,71$ \\
24 & Dimensi kisi teras, cm $\times$ cm &
\end{tabular}


Tabel 2. Data input perhitungan termohidrolika RRI [10].

\begin{tabular}{|c|c|c|c|}
\hline No. & PARAMETER & & NILAI \\
\hline 1 & Pembangkitan panas di teras reaktor, MW & : & 50,0 \\
\hline 2 & Tekanan pendingin ke teras, $\mathrm{kgf} / \mathrm{cm}^{2}$ & : & 8,0 \\
\hline 3 & Temperatur pendingin masuk ke teras, ${ }^{\circ} \mathrm{C}$ & : & 40,5 \\
\hline 4 & $\begin{array}{l}\text { Laju alir pendingin ke teras, } \mathrm{kg} / \mathrm{det} \\
\text { Faktor-faktor puncak daya }\end{array}$ & : & 900 \\
\hline 5 & Faktor puncak daya radial, FR & : & 1,832 \\
\hline 6 & $\mathrm{~F}_{\text {cool }}$ & : & 1,167 \\
\hline 7 & $F_{\text {film }}$ & : & 1,200 \\
\hline 8 & $\mathrm{~F}_{\mathrm{hflx}}$ & : & 1,200 \\
\hline 9 & $\mathrm{~F}_{\text {kelongsong }}, \mathrm{F}_{\text {bond }}, \mathrm{F}_{\text {meat }}$ & : & 1,000 \\
\hline 10 & $\begin{array}{l}\text { Faktor puncak daya aksial, } \mathrm{F}_{\mathrm{A}} \\
\text { Data bahan bakar, } \mathrm{U}_{9} \mathrm{Mo}-\mathrm{Al}\end{array}$ & : & 1,200 \\
\hline 11 & $\rho, \mathrm{g} / \mathrm{cm}^{3}$ & : & 16,336 (Porositas 18\%) \\
\hline 12 & $\mathrm{Cp}, \mathrm{J} / \mathrm{g} .{ }^{\circ} \mathrm{C}$ & : & 0,145 \\
\hline 13 & $\begin{array}{l}\mathrm{k}, \mathrm{W} / \mathrm{cm} .{ }^{\circ} \mathrm{C} \\
\text { Kelongsong, } \mathrm{Al} \mathrm{Mg}_{2}\end{array}$ & : & 0,22 \\
\hline 14 & $\rho, \mathrm{g} / \mathrm{cm}^{3}$ & : & 2,70 \\
\hline 15 & $\mathrm{Cp}, \mathrm{J} / \mathrm{g} \cdot{ }^{\circ} \mathrm{C}$ & : & 0,961 \\
\hline 16 & $\mathrm{k}, \mathrm{W} / \mathrm{cm} \cdot{ }^{\circ} \mathrm{C}$ & : & 2,16 \\
\hline
\end{tabular}

\section{HASIL DAN PEMBAHASAN}

\section{Hasil Perhitungan Laju Alir Teras}

Desain termohidrolika teras RRI-50 bertujuan menyediakan pendinginan yang cukup, agar daya reaktor yang dibangkitkan untuk menghasilkan fluks neutron sesuai UCD terjamin keselamatannya. Desain kecukupan laju alir teras RRI-50 diperlukan guna mendinginkan bahan bakar. Distribusi laju alir sesuai dengan konfigurasi tersebut diperoleh dari hasil perhitungan CAUDVAP. Hasil perhitungan menunjukkan bahwa untuk mendinginkan pembangkitan daya sebesar $50 \mathrm{MW}$, agar dapat menghasilkan fluks neutron rerata sebesar $5 \mathrm{E} 10^{14} \mathrm{n} / \mathrm{cm}^{2} . \mathrm{s}$, diperlukan laju alir sebesar $900 \mathrm{~kg} / \mathrm{s}$. Laju alir tersebut, terbagi dengan fraksi sebesar $84,9 \%$ atau $764 \mathrm{~kg} / \mathrm{s}$ melalui kanal bahan bakar dan elemen kendali, sedangkan sisanya $15,1 \%$ atau $136 \mathrm{~kg} / \mathrm{s}$ melalui 5 kolom air di teras reaktor. Laju alir sebesar ini akan menghasilkan kecepatan pendingin di sisi outlet bahan bakar sebesar $\sim 10 \mathrm{~m} / \mathrm{s}$. Laju alir di dalam teras reaktor dapat diatur dengan mengatur besarnya aliran pendingin yang melalui kolom air menggunakan sumbat (plug) di sisi outlet.

\section{Hasil Perhitungan Termohidrolika Kondisi Tunak di Teras Reaktor}

Panas hasil fisi di dalam bahan bakar dipindahkan secara konduksi ke kelongsong dan selanjutnya dipindahkan secara konveksi paksa ke pendingin, dengan arah aliran dari atas ke bawah. Perhitungan parameter termohidrolika pada kondisi tunak dilakukan dengan menggunakan program PARET-ANL. Distribusi faktor puncak daya aksial dan radial yang digunakan sebagai salah satu input telah menggunakan hasil perhitungan neutronik untuk bahan bakar $\mathrm{U}_{9} \mathrm{Mo}-\mathrm{Al}$ dengan tingkat muat 3,66 gr U/cc. Selain itu juga telah memperhitungkan faktor ketidakpastian dan best estimate untuk memperhitungkan faktor-faktor ketidakpastian hot-spot nuklir dan teknis, $F_{\mathrm{N}}$ dan $F_{\mathrm{E}}$. Kombinasi faktor-faktor tersebut akan menghasilkan overall hot-spot factor, $F$, yang direpresentasikan sebagai kanal terpanas.

Hasil perhitungan termohidrolika kondisi tunak ditunjukkan pada Tabel 3 dan Gambar 2, 3 dan 4. Tabel 3 menampilkan hasil perhitungan parameter termohidrolika pada kondisi tunak menggunakan program perhitungan PARET-ANL dan program komputasi dinamika fluida FLUENT, menggunakan input yang sama. Tabel 3 juga menampilkan hasil perhitungan parameter termohidrolika pada kanal terpanas. Gambar 2 menampilkan profil distribusi temperatur pendingin dan bahan bakar pada kanal terpanas sepanjang arah aksial, dan nilai temperatur terjadinya akhir pendidihan inti, serta terjadinya aliran 2 fasa. Tampak bahwa temperatur kelongsong pada kanal 
terpanas belum mencapai temperatur dua fase maupun temperatur akhir pendidihan inti meskipun delta temperaturnya relatif kecil $\left(17,27^{\circ} \mathrm{C}\right)$. Gambar 3 menampilkan distribusi fluks panas dan marjin keselamatan terhadap rasio burn out. Distribusi pembangkitan fluks panas persatuan luas cukup tinggi, dengan fluks maksimum sebesar $5.90 \mathrm{E}+06 \mathrm{~W} / \mathrm{m}^{2}$. Hal ini menyebabkan panas yang harus dipindahkan dalam kanal pendingin menjadi besar, sehingga sebagai konsekuensinya akan memerlukan kecepatan pendingin yang tinggi. Hasil perhitungan PARET-ANL menunjukkan kecepatan aliran di dalam kanal pendingin mencapai 9,76 m/detik. Temperatur kelongsong yang bersinggungan langsung dengan pendingin, masing-masing sebesar $114,20^{\circ} \mathrm{C}$ dan $164,54^{\circ} \mathrm{C}$. Temperatur ini memiliki marjin yang cukup besar terhadap temperatur dua fasa maupun akhir pendidihan inti karena reaktor beroperasi menggunakan tekanan 8 bar. Gambar 4 menampilkan hasil perhitungan perbedaan temperatur pada kanal rerata dan kanal terpanas. Dari gambar tersebut tampak terdapat perbedaan yang signifikan pada setiap zona mulai dari zona tengah bahan bakar (meat) hingga ke zona aliran pendingin. Perbedaan ini disebabkan karena penggunaan faktor ketidakpastian yang berasal dari faktor fabrikasi dan kesalahan perhitungan, meskipun demikian masih terdapat delta antara temperatur kelongsong dan temperatur dua fasa.

Tabel 3. Hasil perhitungan termohidrolika menggunakan PARET-ANL dan FLUENT

\begin{tabular}{|c|c|c|c|c|}
\hline \multirow[t]{2}{*}{ PARAMETER } & & \multicolumn{2}{|c|}{ KANAL RERATA } & \multirow{2}{*}{$\begin{array}{c}\text { KANAL TERPANAS } \\
\text { PARET-ANL }\end{array}$} \\
\hline & & PARET-ANL & FLUENT & \\
\hline Daya reaktor, MW & : & 50 & 50 & 50 \\
\hline Tekanan inlet, $\mathrm{kg} / \mathrm{cm}^{2}$ & : & 8 & 8 & 8 \\
\hline Laju alir ke teras reaktor, $\mathrm{kg} /$ detik & & 900 & 900 & 900 \\
\hline Temperatur inlet, ${ }^{\circ} \mathrm{C}$ & : & 44,5 & 44,5 & 44,5 \\
\hline Temperatur outlet, ${ }^{\circ} \mathrm{C}$ & : & 70,14 & 61,93 & 91,38 \\
\hline \multicolumn{5}{|l|}{ Temperatur permukaan } \\
\hline kelongsong luar, ${ }^{\circ} \mathrm{C}$ & : & 114,20 & 108,44 & 164,54 \\
\hline Temperatur permukaan meat, ${ }^{\circ} \mathrm{C}$ & : & 120,94 & 110,38 & 176,89 \\
\hline Temperatur meat maks., ${ }^{\circ} \mathrm{C}$ & : & 123,52 & 120,06 & 181,61 \\
\hline Kecepatan pendingin, $\mathrm{m} /$ detik & : & 9,76 & - & 9,76 \\
\hline Perbedaan temperatur i $/ \mathrm{o},{ }^{\circ} \mathrm{C}$ & : & 25,64 & 17,43 & \\
\hline Fluks panas, $\mathrm{W} / \mathrm{cm}^{2}$ & : & 244,97 & & 448,85 \\
\hline Burn-out rasio & : & - & - & 2,01 \\
\hline Instabilitas aliran & : & - & - & 8,45 \\
\hline
\end{tabular}

Tabel 4. Perbandingan hasil perhitungan temperatur maksimum pada kanal rerata dan terpanas

\begin{tabular}{lcccccc}
\hline & \multicolumn{7}{c}{ Temperatur } \\
\cline { 2 - 7 } & $\begin{array}{c}\text { Meat bb. } \\
\left({ }^{\circ} \mathrm{C}\right)\end{array}$ & $\begin{array}{c}\text { Permukaan bb. } \\
\left({ }^{\circ} \mathrm{C}\right)\end{array}$ & $\begin{array}{c}\text { Kelongsong } \\
\left({ }^{\circ} \mathrm{C}\right)\end{array}$ & $\begin{array}{c}\text { Pendingin } \\
\left({ }^{\circ} \mathrm{C}\right)\end{array}$ & $\begin{array}{c}\text { dua fasa } \\
\left({ }^{\circ} \mathrm{C}\right)\end{array}$ & $\begin{array}{c}\text { DNB } \\
\left({ }^{\circ} \mathrm{C}\right)\end{array}$ \\
\cline { 2 - 7 } Kanal terpanas & 181,61 & 176,89 & 164,54 & 91,38 & 181,81 & 212,49 \\
Kanal rerata & 123,52 & 120,94 & 114,20 & 70,14 & 178,94 & 212,49 \\
\hline
\end{tabular}




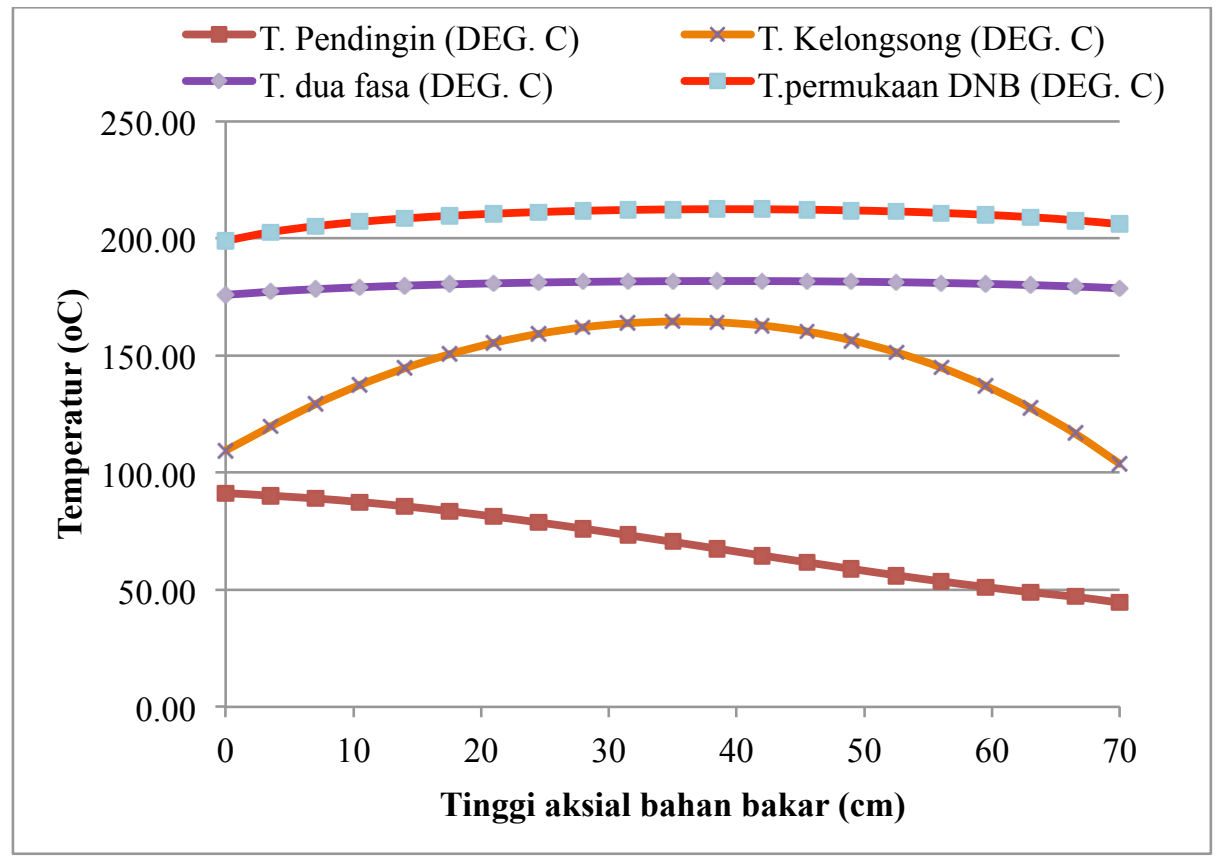

Gambar 2. Distribusi temperatur sepanjang arah aksial bahan bakar

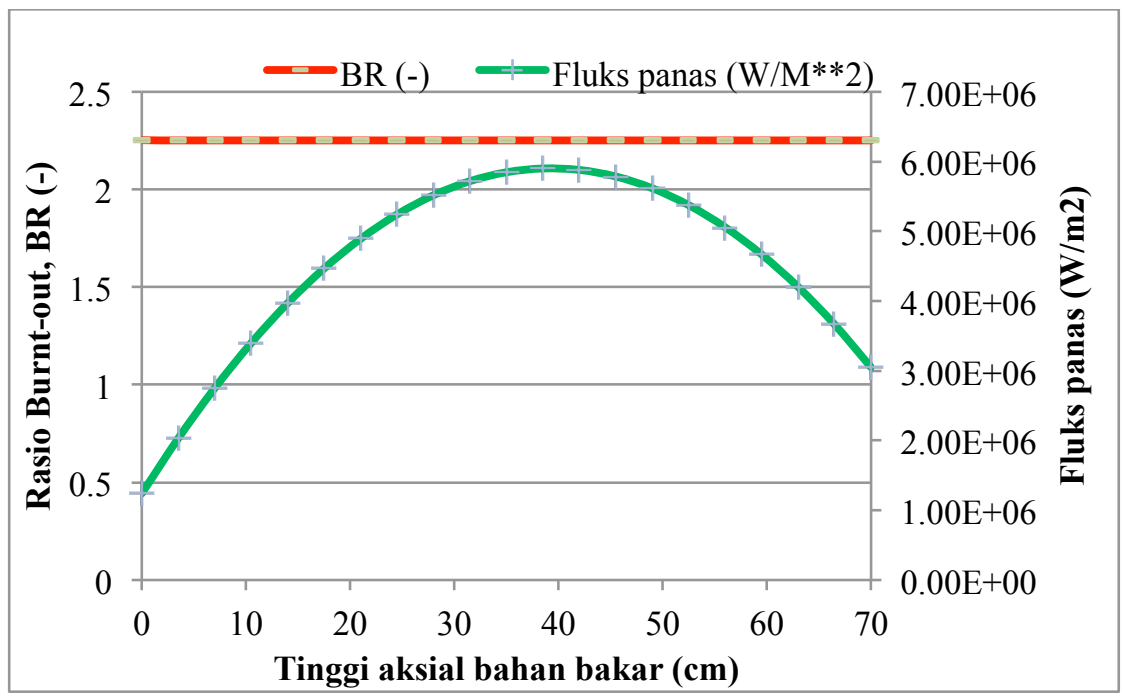

Gambar 3. Distribusi fluks panas dan rasio burn out sepanjang arah aksial bahan bakar 


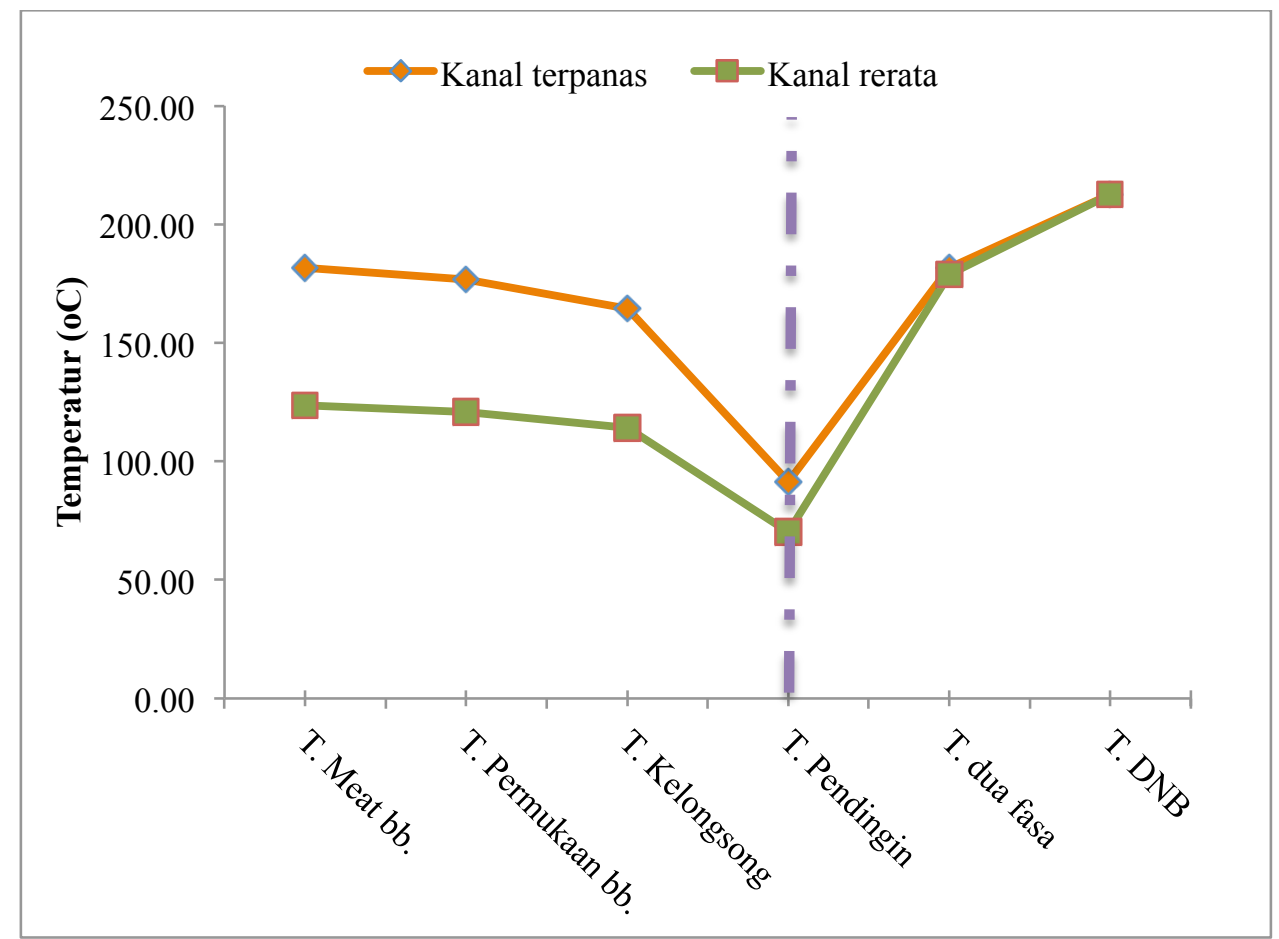

Gambar 4. Perbedaan temperatur pada kanal rerata dan kanal panas di setiap zona

\section{Hasil perhitungan profil temperatur pelat dan pendingin menggunakan CFD}

Untuk menghitung dan menampilkan visualisasi distribusi temperatur sepanjang pelat dan kanal pendingin bahan bakar digunakan program perhitungan CFD-FLUENT. Perhitungan CFDFLUENT memodelkan subkanal, sebagai input digunakan sumber panas dengan densitas panas $1500 \mathrm{~W} / \mathrm{cc}$ dalam meat dan kecepatan aliran panas sebesar $9,76 \mathrm{~m} / \mathrm{s}$ atau setara dengan laju alir teras sebesar $900 \mathrm{~kg} / \mathrm{jam}$. Gambar 5 menampilkan distribusi temperatur dalam subkanal elemen bakar RRI. Gradasi warna pada visualisasi seluruh temperatur pada perhitungan ini berkisar antara $44,5^{\circ} \mathrm{C}$ hingga $122^{\circ} \mathrm{C}$, yang merepresentasikan temperatur inlet pendingin hingga temperatur maksimum tengah bahan bakar (center meat). Gambar 5 menampilkan visualisasi temperatur subkanal aktif sepanjang $70 \mathrm{~cm}$, terlihat bahwa temperature di sisi inlet mengalami peningkatan ke arah sisi outlet, sesuai dengan pembangkitan panas yang tidak saja ke arah radial, melainkan juga ke arah aksial.

Temperatur maksimum pada tengah meat, kelongsong dalam, kelongsong luar dan air pendingin masing-masing sebesar $120,06^{\circ} \mathrm{C} ; 110,38^{\circ} \mathrm{C} ; 108,44^{\circ} \mathrm{C}$ dan $61,93^{\circ} \mathrm{C}$. Dengan asumsi temperatur masukan sebesar $44,5^{\circ} \mathrm{C}$; perbedaan temperatur luaran $(\Delta \mathrm{T})$ mencapai $17,43^{\circ} \mathrm{C}$. Pada kanal rerata dimana faktor kanal panas dianggap sama dengan satu, hasil perhitungan temperatur antara PARET-ANL dan FLUENT menunjukkan hasil yang cukup berkesesuaian. Perbedaan terjadi pada temperatur keluaran kanal pendingin, kelongsong dan tengah bahan bakar, masingmasing sebesar $11,7 \% ; 5,04 \%$ dan $2,8 \%$. Penyelesaian persamaan perpindahan panas dari bahan bakar tipe pelat ke kelongsong dan ke subkanal pendingin pada pelat paralel persegi, yang digunakan antara program PARET ANL dan FLUENT adalah sama. Perbedaan terjadi pada pemodelan, dimana program PARET ANL merupakan program 2 dimensi yang menganggap seluruh aliran pendingin digunakan untuk mengambil panas yang dibangkitkan oleh bahan bakar. Sementara itu program 3 dimensi FLUENT hanya menganggap lapisan pendingin yang bersinggungan langsung dengan kelongsong pelat bahan bakar, yang mengambil panas yang dibangkitkan, sehingga hasil perhitungan FLUENT memberikan temperatur yang lebih tinggi. Meskipun demikian hasil kedua perhitungan ini memiliki perbedaan yang relatif kecil seperti telah dijelaskan di atas. 


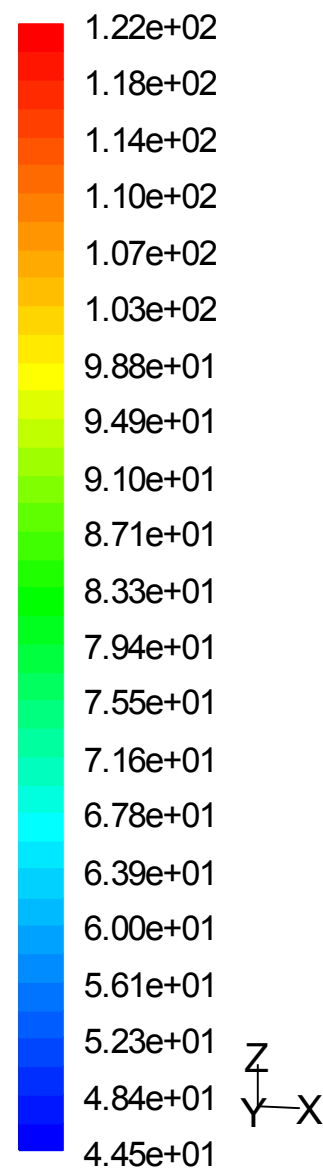

Rentang $44,5-122^{\circ} \mathrm{C}$

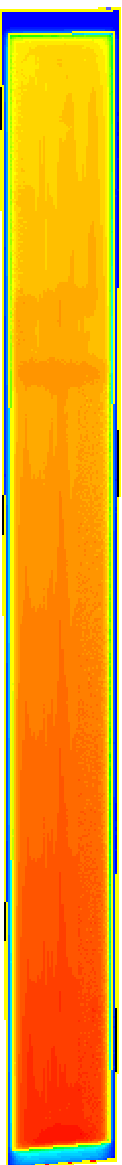

$\mathrm{T}-\max =$

$120,06^{\circ} \mathrm{C}$

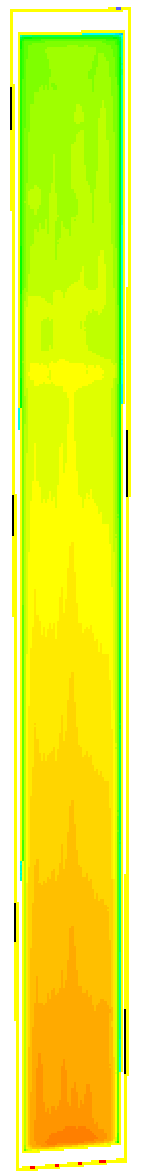

$\mathrm{T}-\max =$ $110,38^{\circ} \mathrm{C}$

Kelongsong dalam

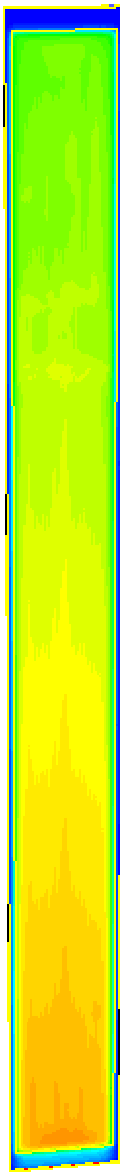

$\mathrm{T}-\max =$ $108,44^{\circ} \mathrm{C}$

Kelongsong luar

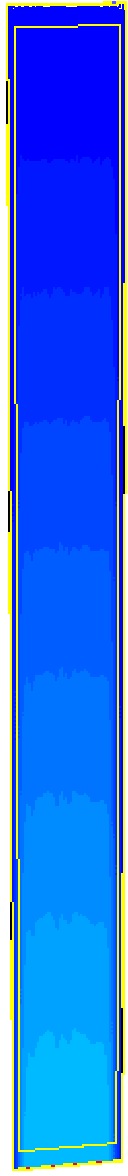

$\mathrm{T}-\max =$ $61,93^{\circ} \mathrm{C}$

Air pendingin

Gambar 5. Distribusi temperatur dalam subkanal elemen bakar RRI-50

\section{Hasil Perhitungan Sistem Pendingin RRI-50}

Untuk mempertahankan pendinginan sirkulasi paksa selama operasi normal, sistem pendingin primer dilengkapi dengan 3 pompa sentrifugal (dua pompa beroperasi, dengan satu pompa standby), untuk mendinginkan panas yang dibangkitkan oleh pelat-pelat bahan bakar, dengan daya total $50 \mathrm{~mW}$. Pompa-pompa tersebut mengalirkan air pendingin primer dengan arah ke bawah (downward) ke dalam teras reaktor melalui hotleg, dan selanjutnya ke delay chamber. Desain tangki tunda (delay chamber) harus mampu meluruhkan radioisotop N-16 pada tingkat aman. Pendingin primer keluar dari delay chamber kemudian memindahkan panasnya ke penukar panas (heat exchanger) dan kembali ke kolam reaktor melalui ring distributor. Dari ring distributor air disemprotkan ke dalam teras reaktor. Sementara itu untuk mempertahankan temperatur air pendingin sekunder, maka panasnya di buang ke menara pendingin secara langsung.

Dalam desain sistem pendingin RRI-50 dilakukan penetapan parameter kunci yang diperoleh dari hasil desain keselamatan teras reaktor, yaitu harus mampu memindahkan panas sebesar $50 \mathrm{~mW}$ tanpa terjadi pendidihan atau aliran dua fase pada pengoperasian reaktor, baik pada moda pendinginan konveksi paksa maupun konveksi alam, serta tersedianya sistem pendingin darurat apabila diperlukan. Desain sistem pendingin RRI-50 dilakukan dengan program ChemCAD 6.1.4., program ini menghitung kesetimbangan neraca massa dan neraca panas mulai dari teras reaktor hingga menara pendingin. Untuk itu perlu ditetapkan terlebih dulu jalur sistem pendingin dengan mempertimbangkan prinsip redundansi, dan diversifikasi yang merupakan prinsip keselamatan yang dianut dalam desain reaktor nuklir, seperti yang ditunjukkan pada Tabel 5. 
Tabel. 5. Batasan desain sistem pendingin RRI-50 [10].

\begin{tabular}{clll}
\hline No. & Parameter & Nilai \\
\hline 1 & $\begin{array}{l}\text { Daya reaktor / panas yang dipindahkan } \\
\text { dari teras reaktor, mW }\end{array}$ & 50 \\
2 & Temperatur inlet teras reaktor, ${ }^{\circ} \mathrm{C}$ & $:$ & 44,5 \\
3 & Tekanan operasi reaktor, bar & $:$ & 8 \\
4 & Laju alir sistem pendingin primer, kg/s & $:$ & 900 \\
5 & Temperatur wet-bulb udara, ${ }^{\circ} \mathrm{C}$ & $:$ & 28 \\
6 & Jumlah pompa pendingin primer, unit & $:$ & $2(+1$ pompa stand by) \\
7 & Kapasitas masing masing pompa & $:$ & 50 \\
& pendingin primer, \% & & 2 (+1 HE redundant) \\
8 & Jumlah heat exchanger, unit & $:$ & Shell and tube \\
9 & Jenis heat exchanger & $:$ & 50 \\
10 & Kapasitas masing masing HE, \% & $:$ & 5 \\
11 & Jumlah menara pendingin, unit & &
\end{tabular}

Proses sistem pendingin utama pada RRI-50 berdasarkan kebutuhan pendingin seperti dijelaskan pada analisis penentuan parameter termohidrolika, didesain dengan menggunakan program perhitungan ChemCAD 6.1.4. Dalam desain ini, sistem pendingin hanya dititik-beratkan pada jalur utama sistem pendingin saja, sehingga belum melibatkan sub-sistem pendingin reaktor.

Neraca massa dan neraca panas untuk desain sistem dan komponen RRI-50 ditunjukkan pada Gambar 6 dan Tabel 6. Pada gambar tersebut ditunjukkan desain diagram alir proses sistem pendingin primer dan sekunder reaktor RRI-50. Pada gambar tersebut, terdapat 2 jalur pendingin yang dilengkapi dengan 2 unit komponen penukar panas dan 4 unit menara pendingin. Desain pendingin reaktor juga didukung dengan satu jalur cadangan sebagai sistem pendingin redundant yang berfungsi sebagai back-up. Menara pendingin didesain memiliki kemampuan pembuangan panas sebesar 50,320 MJoule/s, sedangkan berdasarkan hasil simulasi menggunakan ChemCad 6.4.1 terdapat panas tambahan sebesar 0,262 MJoule/s yang berasal dari putaran pompa-pompa sirkulasi.

Untuk meluruhkan radioisotop N-16 yang terlarut dalam pendingin maka sistem pendingin RRI-50 dilengkapi dengan tangki tunda. Tangki didesain berupa silinder yang di partisi dengan penghalang aliran (baffle) agar waktu tinggal air di dalam tangki tunda memenuhi waktu yang disyaratkan untuk meluruhkan N-16. Pompa sirkulasi sistem pendingin primer dan sekunder (No.: $4,5,16,17)$ dengan tipe jenis sentrifugal 1 stage 3550 RPM dengan head 20,7 m. Alat penukar panas(heat exchanger) tipe shell-tube (No.: 18 dan 19) beban panas 25,03 MJoule/s dengan luas perpindahan panas sebesar 1336,4 $\mathrm{m}^{2}$ [11], dan menara pendingin (No.: 12,13,14,15) jenis Induced draft tower yang beroperasi dalam 2 jalur sistem pendingin. Adapun jalur pendingin cadangan sebagai sistem redundansi dilengkapi dengan unit pompa (No. 7) penukar panas (no.20) dan menara pendingin (no. 21), jalur ini juga diintegrasikan dengan jalur lainnya melalui pengaturan katup-katup.

Tabel 6 menampilkan neraca bahan dan panas desain sistem pendingin RRI-50 setiap komponen di sisi inlet dan outlet, adanya asumsi bahwa tidak terjadi kehilangan panas (proses adiabatis) pada komponen dan pipa, menyebabkan temperatur aliran keluar dari satu komponen dan masuk ke komponen berikutnya sama. Sedangkan adanya reduksi dan ekspansi luas penampang, beda ketinggian serta turbulensi di dalam komponen reaktor dan sistem pendingin menyebabkan adanya beda tekanan aliran seperti ditunjukkan pada Tabel 6 . 


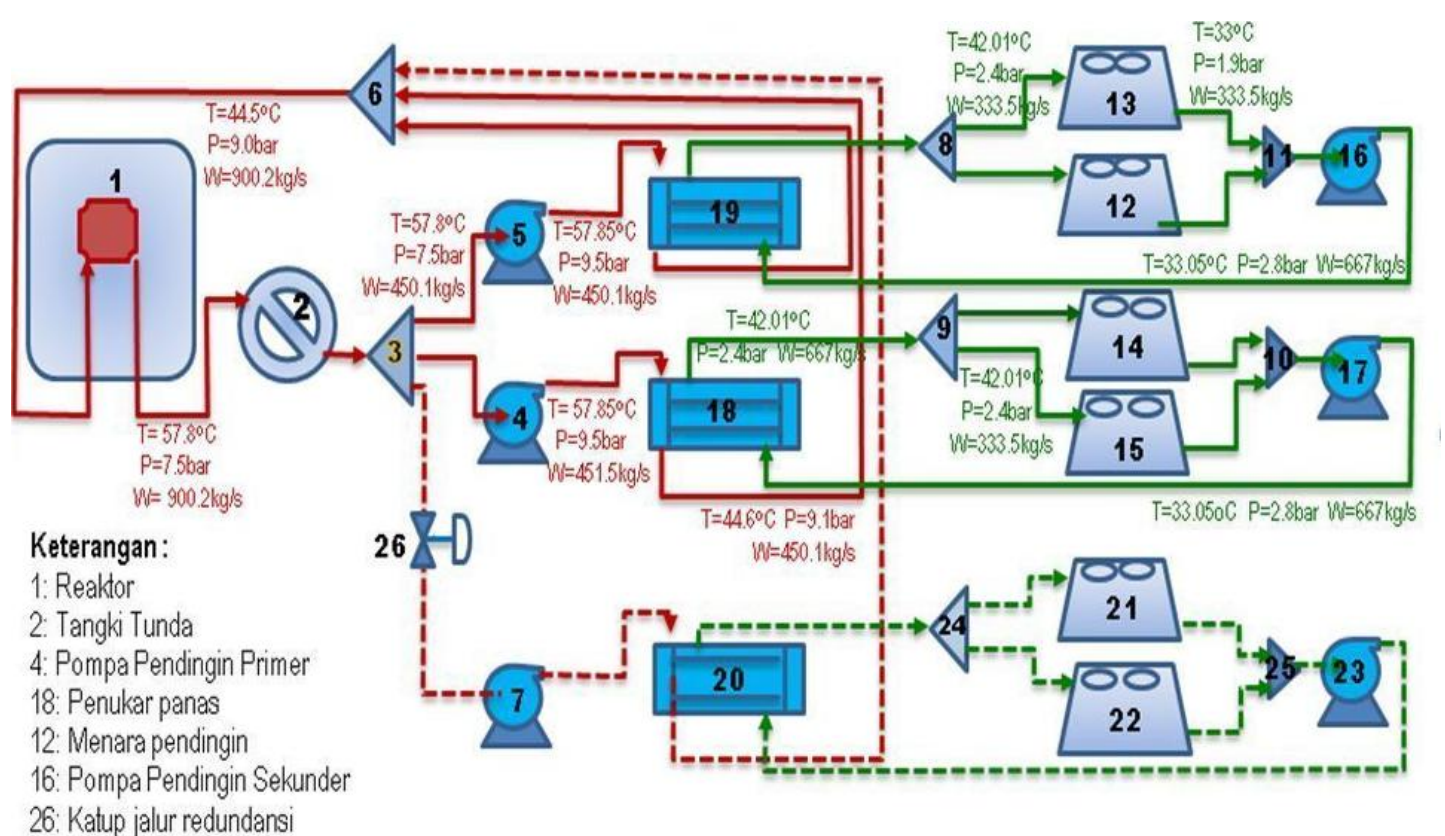

Gambar 6. Desain Diagram Alir Proses Sistem Pendingin RRI-50 [11].

Tabel 6. Neraca massa dan panas desain sistem pendingin RRI-50.

\begin{tabular}{|c|c|c|c|c|c|c|c|}
\hline \multirow{2}{*}{ No. } & \multirow{2}{*}{ Komponen } & \multicolumn{6}{|c|}{ Parameter } \\
\hline & & $\mathrm{T}$ in $\left({ }^{\circ} \mathrm{C}\right)$ & $\mathrm{T}$ out $\left({ }^{\circ} \mathrm{C}\right)$ & $\mathrm{P}$ in (bar) & P out (bar) & $\mathrm{W}$ in $(\mathrm{kg} / \mathrm{s})$ & W out $(\mathrm{kg} / \mathrm{s})$ \\
\hline 1 & Teras reaktor & 44,5 & 57,8 & 9 & 7,5 & 900,2 & 900,2 \\
\hline 2 & Tangki tunda & 57,8 & 57,8 & 7,5 & 7,5 & 900,2 & 900,2 \\
\hline 3 & $\begin{array}{l}2 \text { Pompa } \\
\text { pendingin } \\
\text { sekunder (setiap } \\
\text { pompa) }\end{array}$ & 57,8 & 57,85 & 7,5 & 9,5 & 450,1 & 450,1 \\
\hline 4 & $\begin{array}{l}2 \text { Penukar panas } \\
\text { (HE) tipe } \\
\text { Shell\&Tube } \\
\text { (setiap HE) }\end{array}$ & 57,85 & 42,1 & 9,5 & 2,4 & 451,5 & 450 \\
\hline 5 & $\begin{array}{l}\text { Menara pendingin } \\
(2 \text { jalur })\end{array}$ & 42,1 & 33,05 & 2,4 & 2,8 & 667 & 667 \\
\hline
\end{tabular}

\section{KESIMPULAN}

Desain termohidrolika dan sistem reaktor riset inovatif yang terintegrasi, mulai dari teras, HE hingga menara pendingin serta tangki tunda untuk peluruhan N-16 pada kondisi tunak berhasil dilakukan. Pembangkitan panas yang tinggi $(50 \mathrm{~mW})$ dapat dipindahkan tanpa menyebabkan pendidihan atau aliran dua fase, dengan menerapkan desain teras reaktor bertekanan. Desain RRI50 perlu dilanjutkan ke tahap desain dasar (basic design), hingga diperoleh Basic Engineering Design.

\section{UCAPAN TERIMAKASIH}

Terimakasih disampaikan kepada kelompok Fisika Teras Reaktor yang telah memberikan hasil perhitungan neutronik RRI-50. 


\section{DAFTAR PUSTAKA}

1. Endiah Puji Hastuti dkk. BFTR-PTKRN, "User Criteria Document (UCD) Reaktor Riset Inovatif", BATAN-RKN-06-2010.

2. Saha P., Aksan N., Andersen J., Yan J., Simoneau J.P., LeungL., Bertrand F.,AotogK., KamidegH., Issues and future direction of thermal-hydraulics research and development in nuclear power reactors, Nuclear Engineering and Design 2013; 264:3-23.

3. Daeseong Jo, Jonghark Park, Heetaek Chae, Development of thermal hydraulic and margin analysis code for steady state forced and natural convective cooling of plate type fuel research reactors, Progress in Nuclear Energy 2014;71:39-51.

4. Qing Lu, Suizheng Qiu, SuG.H., Development of a thermal-hydraulic analysis code for research reactors with plate fuels, Annals of Nuclear Energy 2009;36:433-447.Ramin

5. Barati, Saeed Setayeshi, Functional reliability evaluation of an MTR-pool type research reactor core using the load-capacity interference model, Annals of Nuclear Energy2013; 58:151-160.

6. Kazem Ardaneh, Salman Zaferanlouei, A lumped parameter core dynamics model for MTR type research reactors under natural convection regime, Annals of Nuclear Energy 2013;56: 243-250.

7. Abhinav Dixita, Takashi Hibikia, Mamoru Ishii, Kouichi Tanimoto, Yoshiyuki Kondoh, Koki Hibi, Experimental stability maps for a two-phase natural circulation reactor with and without void-reactivity feedback effect, Nuclear Engineering and Design 2013; 261:181200.

8. Jian Maa, Longjian Li, Yanping Huang, Xiaozhong Liu, Experimental studies on singlephase flow and heat transfer in a narrowrectangular channel, Nuclear Engineering and Design 2011;241:2865-2873.

9. Jian Zhang, Xiuzhong Shen, Yasuyuki Fujihara, Tadafumi Sano, Toshihiro Yamamoto, Ken Nakajima, Experimental study on the safety of Kyoto University Research Reactor at natural circulation cooling mode, Annals of Nuclear Energy 2015;76:410-420.

10. Surip Widodo dkk. BFTR-PTKRN, "Desain Konseptual Reaktor Riset Inovatif", Ident. No. 1/CD01/TRRI/2013.

11. Sukmanto Dibyo,Endiah Puji Hastuti, Ign. Djoko Irianto, Analisis desain sistem pendingin dan unit komponen pada reaktor RRI-50, Jurnal Teknologi Reaktor Nuklir Tri Dasa Mega, $2015 ; 17: 19-30$. 